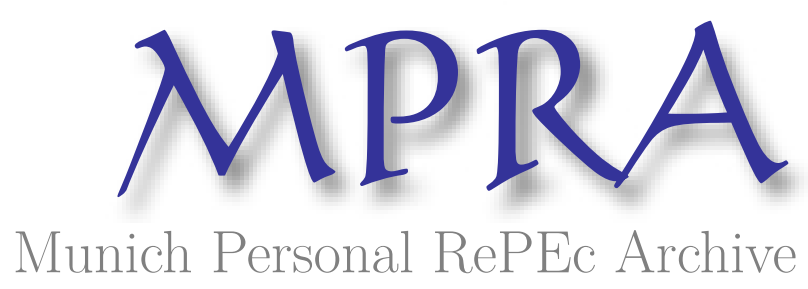

\title{
House Prices and Consumption
}

Song, In Ho

The Ohio State University

28 November 2010

Online at https://mpra.ub.uni-muenchen.de/27481/

MPRA Paper No. 27481, posted 17 Dec 2010 00:54 UTC 


\title{
House Prices and Consumption *
}

\author{
In Ho Song ${ }^{\dagger}$
}

November 2010

\begin{abstract}
I study the consumption responses of heterogeneous households following changes in both house prices and interest rates. I show the common assumption that household period utility is separable in housing and consumption can be consistent with the observed co-movement between these two series only in the absence of housing transaction costs. When these costs are introduced into dynamic stochastic general equilibrium (DSGE) models characterized by separable preferences, consumption no longer increases after a rise in house prices. As it is well known, transaction costs are an important ingredient in house sales. I address this issue by developing a model that allows for non-separable preferences in housing and consumption alongside housing transaction costs.

The results of my model closely match the aggregate data. Furthermore, it predicts that credit-constrained households will be substantially more responsive to changes in both house prices and interest rates than unconstrained households. Following a rise in house prices, consumption among constrained households increases by far more than the consumption of unconstrained households. Following a rise in interest rates, constrained households' consumption falls by more than that of unconstrained households. I trace this differing responsiveness in consumption to the house loan-to-value ratio of credit-constrained households. Higher loan-to-value ratios imply larger differences in their elasticity of response relative to unconstrained households. I also find that these differences widen with the degree of complementarity between housing and consumption. These predictions of my model are confirmed by household data from the Consumer Expenditure Surveys.
\end{abstract}

JEL No. C1,C10, D50, E30, E44, E52, G10, G12, R21

Keywords: DSGE, House Prices, Heterogeneous Households, Elasticity of Intra-Temporal Substitution (EIS), Complementarity, Credit

\footnotetext{
${ }^{*}$ I thank Aubhik Khan for his guidance and comments. I also thank Paul Evans, Massao Ogaki, Julia Thomas and Kerry Tan for their comments and advice. I am responsible for any remaining errors.

${ }^{\dagger}$ Department of Economics, The Ohio State University, song.235@osu.edu
} 


\section{Introduction}

A house not only serves as an important asset, but it also is a large component of overall consumption expenditure. In recent years, researchers have begun to study the role of house prices in explaining movements in macroeconomic series. I develop a dynamic stochastic general equilibrium (DSGE) model that incorporates two key components. The first is housing transaction costs. The second component is nonseparable preferences over housing and consumption. Households differ in that unconstrained households are not affected by their house collateral value, while constrained households are affected by the collateral value of their houses. Constrained households are assumed to be relatively impatient compared to unconstrained households.

Complementarity between housing and consumption exists when the elasticity of intratemporal substitution (EIS) is less than unity. In this paper, the EIS is estimated at 0.59 through minimum distance estimation. This finding of complementarity is consistent with previous finding in NIPA data (Song (2009)), PSID data (Flavin and Nakagawa (2004), Siegel (2004), and Li, Liu and Yao (2008)), CEX data (Stokey (2007)) ${ }^{1}$, and data from the Housing Allowance Demand Experiment (Hanushek and Quigley (1980)). Hence, introducing complementarity under nonseparable preferences over housing and consumption is justified based on the data.

Along with complementarity, proportional housing transaction costs are also crucial in the analysis of housing and consumption. Eberly (1994) and Lam (1989) show the importance of transaction costs as a determinant of durable goods consumption. Furthermore, Grossman and Laroque (1990) argue that transaction costs significantly affect the number of house sales. They show that a transaction cost that is 5 percent of the value of the existing house implies an average time between purchases of 20 to 30 years. It follows that models without transaction costs may not capture an essential aspect influencing movements in the data, and their predicted price movements may be misleading.

Most of the existing model-based macroeconomic literature rules out the possibility of complementarity between housing and non-housing consumption by adopting separable

\footnotetext{
${ }^{1}$ Using NIPA data from 1970 to 2009, Song (2009) finds evidence at complementarity. Flavin and Nakagawa (2004) apply complementarity to asset pricing implications. They find that the EIS is less than one, arguing housing and consumption are not separable in preferences. In fact, they estimate the EIS to be 0.13. Li, Liu and Yao (2008) estimate the EIS at 0.33 through the Method of Simulated Moments (MSM) using PSID data. Stokey (2007) also estimates the EIS at 0.23 and 0.45 using CEX expenditure data.
} 
preferences, which are usually based on a log utility function as in Aoki et al. (2004) and Iacoviello (2005). Elsewhere, Piazzesi et al. (2007) find evidence suggesting that housing and consumption could be substitutes. They do not directly consider housing, but instead consider the elasticity of substitution between durable goods and nondurable goods. They adopt a parameter value ranging in the interval $[1.04,1.43]$ with 95 percent confidence, as in Ogaki et al. (1998). However, the estimate of that elasticity of substitution is misleading about the elasticity between consumption and housing services. ${ }^{2}$

This paper is related to the seminal contribution of Iacoviello (2005). His analysis of housing assumes separable preferences between consumption and housing, and abstracts from housing transaction costs. When housing transaction costs are introduced with separable preferences into the Iacoviello (2005) model, consumption no longer increases following a rise in house prices. This is inconsistent with the empirical evidence showing a positive co-movement between house prices and consumption.

Recognizing the importance of both complementarity and transaction costs, I address this issue by developing a DSGE model that allows for realtor fees and nonseparable preferences over housing and consumption. In my model, transaction costs, complementarity and house loan-to-value ratios drive different consumption responses across creditconstrained and unconstrained households. Complementarity between housing services and non-housing consumption makes the model consistent with the co-movement seen in the data. The transmission mechanism of house prices is as follows. Suppose house prices rise, this increases both the values of collateral, for credit-constrained households, and net worth. As a result, spending on an consumption and housing rises. The increase in housing demand leads to a further rise in house prices. Transaction costs abate this circular process somewhat. Nonetheless, the fundamental co-movement between housing and consumption continues to deliver an amplification effect.

I find that constrained households are substantially more responsive to changes in both house prices and interest rates than unconstrained households. For example, a rise in house prices increases the consumption of constrained households by far more than the consumption of unconstrained households. Transaction costs dampen the response of constrained households to an increase in house prices. Furthermore, following a rise in interest rates, the consumption of constrained households falls by more than that of

\footnotetext{
${ }^{2}$ Song (2009) finds a significant estimate of the housing versus non-housing consumpiton elasticity to be 0.19. This finding of complementarity there is robust to a variety of estimation methods including Dynamic OLS (DOLS), Canonical Co-integrating Regression (CCR) and Fully Modified OLS (FMOLS).
} 
unconstrained households. This difference in the responsiveness of consumption is driven by the house loan-to-value ratio characterizing credit-constrained households. Higher loanto-value ratios imply larger differences in the consumption response across constrained and unconstrained households.

Stronger complementarity also widens the gap between the consumption responses across the two groups of households. A rise in the interest rate leads constrained households to further decrease contemporaneous consumption. Higher house loan-to-value further magnifies the effect of changes in interest rates, so that the real economy becomes more volatile with respect to house prices and consumption. I confirm these predictions of my model using household data from the Consumer Expenditure Surveys.

The remainder of this paper is as follows. In section 2, I provide a set of empirical regularities regarding house prices and the demand for consumption goods and housing. There, I document the positive correlation between house prices and consumption that I seek to address. Next, in section 3, I construct a DSGE model allowing for both housing transaction costs and nonseparable preferences over housing and non-housing consumption. In section 4, I calibrate my model using long-run average and shares of macroeconomic series. Next, I estimate the structural parameter governing the consumption-housing elasticity using a minimum distance method that minimizes the difference between impulse responses from the model versus the data. Results are presented in section 5 and section 6 . There, I show that my model generates time series consistent with those in the data. I also evaluate my model's comparative statics predictions regarding house loan-to-value ratios and housing transaction costs. I show that, following an increase in the interest rate, higher loan-to-

values lead to more volatile responses in both house prices and consumption. Section 7 concludes.

\section{Stylized Facts}

In 2007, the value of real estate in households amounted to over $\$ 20$ trillion, which is 1.4 times greater than nominal annual gross domestic product (GDP). The mortgage related market, totaling $\$ 8.6$ trillion in 2007 , has grown aggressively to become a dominant component of financial markets since 1997. New issuance of mortgage related securities amounted to over $\$ 2.1$ trillion, which is 272 percent of outstanding Treasuries and 180 
percent of the corporate bond market. ${ }^{3}$

Throughout the post-war period, US house prices, residential investment and GDP have co-moved. Figure 1 shows the co-movement of house prices, consumption and residential investment. At the period of each recession, all variables tend to move downward together. Residential investment is very volatile. In particular, residential investment is severely affected during a recession. In 2005, the contribution of residential construction to GDP was 6.3 percent; by 2009 this had fallen to 2.4 percent. $^{4}$

Figure 1: Co-movement of Housing Prices, Residential Investment and Consumption

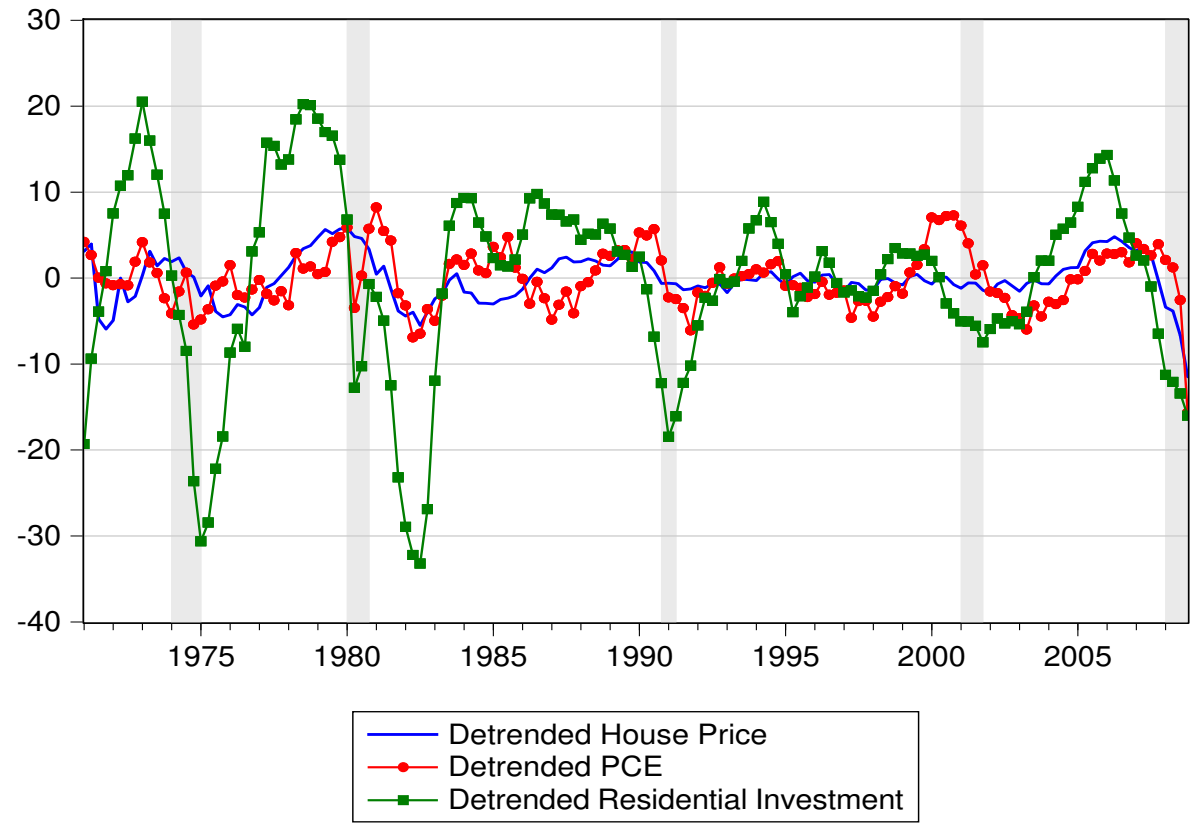

In Figure 2, I examine the direct relationship between house prices and consumption using a scatter-plot of de-trended personal consumption expenditure (PCE) and de-trended house prices (CMHPI). The data is from the Bureau of Economic Analysis (BEA) and Freddie Mac, and covers the 1970 to 2009 period. I use an HP-Filter to de-trend the data. The correlation between house prices and consumption is 0.42 . As house prices increase (decrease), households are more (less) likely to consume. Given the positive correlation

\footnotetext{
${ }^{3}$ These observations are drawn from SIFMA data, which is available at: www.sifma.org/uploadedFiles/Research/Statistics/SIFM $A_{U}$ SBondMarketOutstanding.pdf

${ }^{4}$ See "The recession and the Housing Drag" in Wall Street Journal, September 21, 2010.
} 
between house prices and both consumption and residential investment (housing demand), housing and consumption appear to move as complements.

Figure 2: Scatterplot of Detrended CMHPI against Detrended PCE

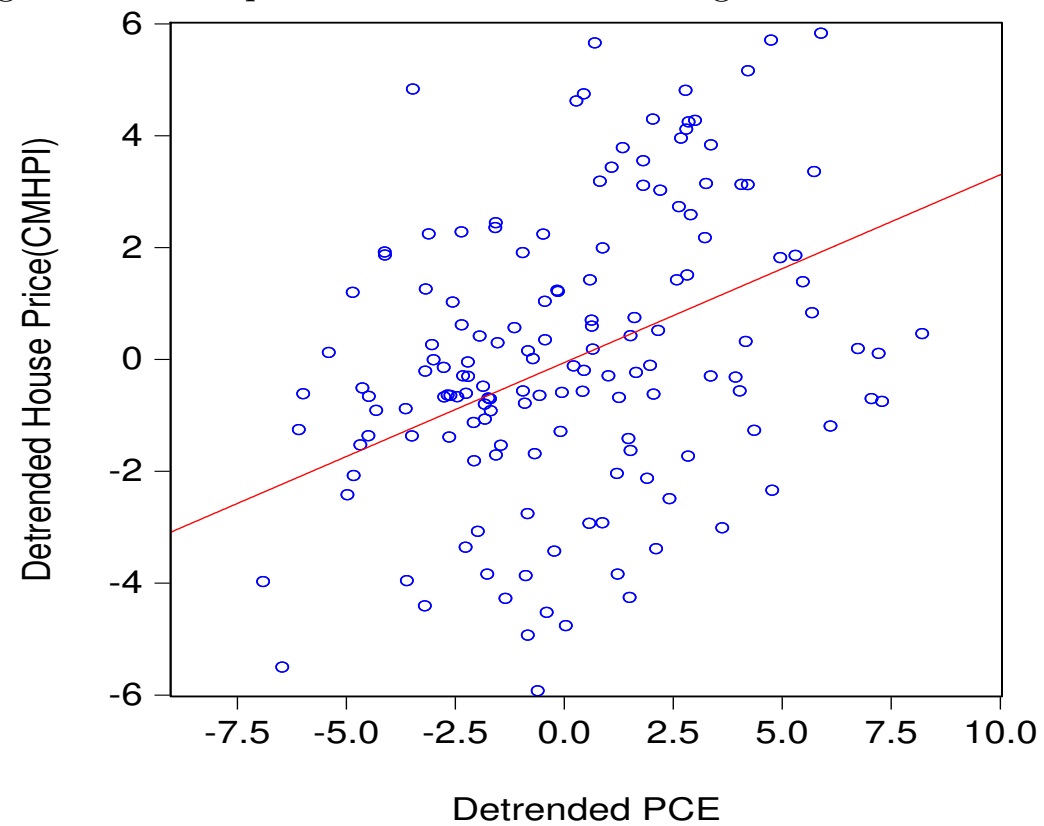

Houses are different from other durable goods in several important respects. First, changes in housing stocks incur substantial transaction costs proportional to house values. Second, the average housing depreciation rate (1.6 percent) is very small compared to the depreciation rates of other durable goods (averaging 21 percent). Third, with a required down payment, houses are highly leveraged. Fourth, house values are three times as big as all other durable good stocks. Fifth, houses perform a dual role; they are both an investment asset and a shield against fluctuations in stock prices. ${ }^{5}$ In the section below, I develop a model that captures these special qualities unique to housing.

\section{The Model}

The economy is populated by unconstrained households, constrained households, entrepreneurs, retailers and the central bank. Households are heterogeneous in that un-

\footnotetext{
${ }^{5}$ Robert B. Couch(2004) examines the correlation between house prices and stock returns and finds that it is relatively low
} 
constrained households are unaffected by their collateral, provide loans to constrained households, receive lump sum profits from the ownership of retail firms and accumulate realtor fees. Constrained households are affected by house collateral, receive loans from unconstrained households and they are assumed to be relatively impatient in comparison to unconstrained households. Since proportional transaction costs come from realtor fees, constrained households and entrepreneurs have to pay transaction costs to unconstrained households (realtors), whenever there are housing transactions. Entrepreneurs produce intermediate goods using labor, houses and capital as inputs. Retailers, who buy intermediate goods from entrepreneurs and sell final consumption goods to households, are monopolistically competitive and have infrequent opportunities to adjust prices. The central bank takes the nominal interest rate as a policy instrument. Monetary policy is assumed to follow a Taylor rule responding to past inflation and past output.

The model in this paper follows the same structure as Iacoviello (2005). However, it differs in two crucial ways. First, the household utility function is not separable in housing and consumption. Introducing nonseparable preferences is a critical extension to the analysis of housing in macroeconomics. Complementarity in preferences is suggested by both micro and macro data. Second, introducing housing transaction costs leads to important changes given the nonseparable utility function. Transaction costs reduce the effect of house prices on consumption. ${ }^{6}$

In this paper, housing transaction costs proportional to the sale price of houses are introduced into the budget constraints of households and entrepreneurs. Housing transaction costs capture two important facts. First, new house purchases heavily depend on the sale of existing housing. These purchases are associated with realtor fees. Second, realtor fees reduce the effect of changes in house prices on consumption. As a result, transaction costs can dampen movements in house prices. In fact, introducing transaction costs moves the model closer to the data, as will be shown in section 5 and 6 .

\subsection{Unconstrained Households}

Unconstrained households receive utility from consumption and housing services derived from the quantity of housing stock they hold. They also provide labor for production. Their preference for consumption and housing services is represented by a time separable

\footnotetext{
${ }^{6}$ Furthermore, transaction costs are important determinants of durable good consumption (Eberly (1994)) and (Ogaki and Reinhart (1997)).
} 
constant elasticity of substitution (CES) utility function. Unconstrained households maximize the following objective function:

$$
\max _{\left\{b_{1, t} C_{1, t}, H_{1, t}, N_{1, t}\right\}_{t=0}^{\infty}}\left\{E_{0} \sum_{t=0}^{\infty} \beta_{1}^{t} \frac{1}{1-\varsigma}\left[\left\{C_{1, t}^{\frac{\varepsilon-1}{\varepsilon}}+j_{t}\left(H_{1, t}\right)^{\frac{\varepsilon-1}{\varepsilon}}\right\}^{\frac{\varepsilon}{\varepsilon-1}}\right]^{1-\varsigma}-\frac{N_{1, t}^{\eta_{1}}}{\eta_{1}}\right\},
$$

where $E_{0}$ denotes the expectation operator. ${ }^{7} C_{1, t}$ denotes nondurable consumption. $H_{1, t}$ denotes the stock of housing. ${ }^{8}$ The discount factor $\beta_{1}$ for unconstrained households is assumed to be greater than that of constrained households, or $0<\beta_{2}<\beta_{1}<1$. The parameter $\varepsilon$ is the elasticity of intratemporal substitution between housing and nondurable consumption. As long as $\varepsilon$ is less than one, housing and consumption are complements. The parameter $\varsigma$ is the curvature of the utility function, which can also be interpreted as the households' coefficient of relative risk aversion. Households allocate their time between labor hours, $N_{1, t}$ and leisure, $L_{1, t}$. Their endowment of time is one, hence $N_{1, t}+L_{1, t}=1$. I also assume that the housing demand shock, $j_{t}$, follows the stochastic process:

$$
\ln j_{t}=\left(1-\rho_{j}\right) \ln \bar{j}+\rho_{j} \ln j_{t-1}+\varepsilon_{j, t}
$$

where $\bar{j}>0, \rho_{j} \in(-1,1)$ measures the persistence of the shock, and $\varepsilon_{j, t}$ is independent and identically distributed i.i.d. $\sim N\left(0 ; \sigma_{j}^{2}\right)$ with mean zero and variance $\sigma_{j}^{2}$.

Each period, unconstrained households choose a level of nondurable consumption, houses and hours of work, given the period budget constraint. The budget constraint is given by

$$
P_{t} C_{1, t}+\left(H_{1 t}-H_{1 t-1}\right) Q_{t}+R_{t-1} B_{1, t-1}+\varphi_{1} Q_{t} H_{1 t-1}=W_{1, t} N_{1, t}+B_{1, t}+F_{t}+S_{t}
$$

Households begin with a stock of housing, which has the nominal market value of $H_{1 t-1} Q_{t}$. They also receive lump sum profits, $F_{t}$, from the ownership of retail firms, and nominal realtor fees, $S_{t}$, from constrained households and entrepreneurs. $S_{t}$ follows

$$
S_{t}=\varphi_{e} Q_{t} H_{e t-1}+\varphi_{1} Q_{t} H_{1 t-1}+\varphi_{2} Q_{t} H_{2 t-1},
$$

\footnotetext{
${ }^{7}$ Throughout the paper, the subscripts 1,2 , and $e$ refer to unconstrained households, constrained households, and entrepreneurs, respectively.

${ }^{8}$ Housing services are assumed to be proportional to the stock of housing.
} 
where $\varphi_{1}$ is zero because unconstrained households are realtors, while $\varphi_{e}$ and $\varphi_{2}$ denote realtor fees, which are proportional to the sale value of houses. I assume that unconstrained households lend in nominal terms, $-B_{1, t}$. In return, they receive nominal amount of $R_{t-1} B_{1, t-1}$. $R_{t-1}$ is the nominal interest rate. It is assumed that houses do not depreciate. Using a numeraire $P_{t}$, we can obtain the real budget constraint from the nominal budget constraint above:

$$
C_{1, t}+\left(H_{1 t}-H_{1 t-1}\right) q_{t}+\frac{R_{t-1}}{\pi_{t}} b_{1, t-1}+\varphi_{1} q_{t} H_{1 t-1}=w_{1, t} N_{1, t}+b_{1, t}+f_{t}+s_{t},
$$

where $w_{1, t}$ is the real wage households earn from their labor supply, $q_{t}$ is the real house price, and $\pi_{t}$ denotes inflation, or $\pi_{t}=\frac{P_{t}}{p_{t-1}}$. Since the nonseparable utility function is associated with transaction costs, the curvature, $\varsigma$, can be greater than, equal to or less than the inverse of the marginal rate of intertemporal elasticity of substitution. I define the curvature of the utility function as $\varsigma=\frac{1}{\sigma}$. When $\varepsilon$ is equal to $\sigma$, the utility function becomes separable. When the limit is taken as $\varepsilon$ goes to one, the utility function becomes the CobbDouglas specification. The household optimization problem is to choose $b_{1, t}, C_{1, t}, H_{1, t}$, and $N_{1, t}$ to maximize (1), subject to constraints (2) and (3).

The first order conditions lead to the following two optimality conditions are derived:

$$
1=E_{t}\left(\frac{U_{C_{1, t+1}}}{U_{C_{1, t}}} \frac{\beta_{1} R_{t}}{\pi_{t+1}}\right)
$$

where $U_{C_{1, t}}=\left\{C_{1, t}^{\frac{\varepsilon-1}{\varepsilon}}+j_{t}\left(H_{1, t}\right)^{\frac{\varepsilon-1}{\varepsilon}}\right\}^{\frac{\sigma-\varepsilon}{\sigma(\varepsilon-1)}} C_{1, t}^{\frac{-1}{\varepsilon}}$, and

$$
\frac{U_{H_{1, t}}}{U_{C 1, t}}=q_{t}\left(1+\varphi_{1}\right)-\left(\frac{\pi_{t+1}}{R_{t}}\right) q_{t+1}
$$

where $U_{H_{1, t}}=\left\{C_{1, t}^{\frac{\varepsilon-1}{\varepsilon}}+j_{t}\left(H_{1, t}\right)^{\frac{\varepsilon-1}{\varepsilon}}\right\}^{\frac{\sigma-\varepsilon}{\sigma(\varepsilon-1)}}\left(H_{1, t}\right)^{\frac{-1}{\varepsilon}} j_{t}$. Equation (4) is the standard Euler equation. The intertemporal marginal rate of substitution, weighted by the nominal interest rate and discounted by $\beta_{1}$ equals one. Equation (5) determines the marginal rate of substitution between housing and consumption. These two equations can be combined into

$$
\frac{C_{1}}{H_{1}}=\left(q_{t}\right)^{\varepsilon}\left(\frac{\left(1+\varphi_{1}\right)}{j_{t}}-\frac{\pi_{t+1}}{j_{t} R_{t}} \frac{q_{t+1}}{q_{t}}\right)^{\varepsilon}
$$


Equation (6) gives the optimal ratio of consumption to housing, which is related to house prices, transaction costs, housing demand shocks and the nominal interest rate. The higher the interest rate is, the greater consumption rises relative to housing, because houses are more sensitive to the interest rate. The higher the positive housing demand shock is, the less consumption relative to housing is likely to be, because housing is more valuable.

\subsection{Constrained Households}

The optimization problem for constrained households is

$$
\max _{\left\{b_{2, t} C_{2, t}, H_{2, t}, N_{2, t}\right\}_{t=0}^{\infty}} E_{0} \sum_{t=0}^{\infty}\left(\beta_{2}\right)^{t} \frac{1}{1-\varsigma}\left[\left\{C_{2, t}^{\frac{\varepsilon-1}{\varepsilon}}+j_{t}\left(H_{2, t}\right)^{\frac{\varepsilon-1}{\varepsilon}}\right\}^{\frac{\varepsilon}{\varepsilon-1}}\right]^{1-\varsigma}-\frac{N_{2, t}^{\eta_{2}}}{\eta_{2}}
$$

subject to

$$
C_{2, t}+I_{h 2 t}+\frac{R_{t-1}}{\pi_{t}} b_{2, t-1}=w_{2, t} N_{2, t}+b_{2, t}
$$

where

$$
H_{2 t}=q_{t} H_{2 t-1}+I_{h 2 t}-\varphi_{2} q_{t} H_{2 t-1}
$$

and

$$
R_{t} b_{2 t} \leq m_{2} E_{t}\left(q_{t+1} \pi_{t+1} H_{2 t}\right) .
$$

For constrained households, housing transactions incur realtor fees, $\varphi_{2} q_{t} H_{2 t-1}$. The transaction costs are proportional to the value of house sales and are paid to unconstrained households. Since it is assumed that constrained households discount the future more heavily than unconstrained households, equation (9), which represents the collateral constraint, binds. As in Kiyotaki and Moore (1997), when debtors default on obligations, creditors repossess houses by paying $\left(1-m_{2}\right) \beta q_{t+1} \pi_{t+1} H_{2, t}$. Hence, $\left(1-m_{2}\right)$ can be interpreted as a down-payment ratio. The loan-to-value ratio is denoted as $m_{2}$, where $0 \leq m_{2} \leq 1$. Liquidation, however, takes times and bears costs. The collateral constraint implies that mortgages cannot exceed the house value. I assume that the housing demand shock, $j_{t}$, is common to both unconstrained households and constrained households following the stochastic process.

The first order conditions imply the following Euler equation and housing price equa- 
tion:

$$
\begin{gathered}
U_{C_{2, t}}=R_{t} \lambda_{2, t}^{m}+U_{C_{2, t}+1} \frac{R_{t}}{\pi_{t+1}} \beta_{2}, \\
q_{t}=\frac{U_{H_{2, t}}}{\left(1+\varphi_{2}\right) U_{C_{2, t}}}+\frac{\beta_{2}\left(1-\delta_{h 2}\right)}{\left(1+\varphi_{2}\right)}\left(\frac{U_{C_{2, t+1}}}{U_{C_{2, t}}}\right) q_{t+1}+\frac{\lambda_{2, t}^{m}}{U_{C_{2, t}}} \frac{m_{2 t} E_{t} q_{t+1} \pi_{t+1}}{\left(1+\varphi_{2}\right)},
\end{gathered}
$$

where $U_{C_{2, t}}=\left\{C_{2, t}^{\frac{\varepsilon-1}{\varepsilon}}+j_{t}\left(H_{2, t}\right)^{\frac{\varepsilon-1}{\varepsilon}}\right\}^{\frac{1-\sigma \varepsilon}{\varepsilon-1}} C_{2, t}^{\frac{-1}{\varepsilon}}$, and $U_{H_{2, t}}=\left\{C_{2, t}^{\frac{\varepsilon-1}{\varepsilon}}+j_{t}\left(H_{2, t}\right)^{\frac{\varepsilon-1}{\varepsilon}}\right\}^{\frac{1-\varepsilon \sigma}{\varepsilon-1}}\left(H_{2, t}\right)^{\frac{-1}{\varepsilon}} j_{t}$. $\lambda_{2, t}^{m}$ is the Lagrange multiplier associated with the borrowing constraint. House prices depend on $\varepsilon, \sigma$, and housing demand preferences. Composition risks, which are ratio fluctuations in the share of housing to consumption affect house prices. Consumption risks are also associated with house prices. The realtor fee rate, $\varphi_{2}$, affects house prices negatively. When $\varepsilon$ rises relative to $\sigma$, households are more willing to substitute housing services and nondurable consumption within a period than they are to substitute overall consumption between the periods. When $\varepsilon$ is equal to $\sigma$, house prices purely are related to composition risk and consumption risk. House prices in the steady state satisfy

$$
q=\frac{\bar{j}}{\left(1+\varphi_{2}\right)-\beta_{2}-\left(\beta_{1}-\beta_{2}\right) m_{2}}\left(\frac{C_{2}}{H_{2}}\right)^{\frac{1}{\varepsilon}} .
$$

The house price depends on the housing demand shock, transaction costs, loan-to-values, and the ratio of consumption to house. Complementarity ${ }^{9}, \varepsilon$, is also an important element in determining asset prices. The denominator implies the average of discount factors across unconstrained households and constrained households. House prices increase when house loan-to-value $m_{2}$ increases and when the realtor fee $\varphi_{2}$ decreases, ceteris paribus. When the transaction costs are equal to zero, house prices are determined by the discount factor, consumption share to houses and $\varepsilon$. From the budget constraint, net worth is used to finance the difference of new debt and the next unit of house. Selling one's existing house affects their net worth, which is used to purchase new stock of houses. The difference between the price of new house and net worth is the households's new debt. Hence, houses for constrained households satisfy,

$$
H_{2, t}=\frac{1}{E_{t}\left(q_{t}-\frac{m_{2} q_{t+1} \pi_{t+1}}{R_{t}}\right)}\left(q_{t} H_{2, t-1}-\frac{R_{t} b_{2, t-1}}{\pi_{t}}\right) .
$$

\footnotetext{
${ }^{9}$ Since in this paper, the elasticity of intratemporal substitution, $\varepsilon$, is estimated at 0.592 , it can be interpreted as complementarity.
} 
This equation is consistent with the result of Kiyotaki and Moore (1997). As the loan-tovalue, $m_{2}$, rises, house prices increase. This occurs because a higher loan-to-value results in higher housing demand. As house prices rise from both date $t$ and $t+1$, the current net worth, $q_{t} H_{2, t-1}-\frac{R_{t} b_{2, t-1}}{\pi_{t}}$, and the collateral value, $\frac{q_{t+1} \pi_{t+1}}{R_{t}}$, increase, which induces an increase in housing demand. The extent to which houses can be used as collateral determines how much the conventional law of demand is overturned. In fact, an increase in house prices induces a rise in housing demand through the collateral effect. For the extreme case of no collateral value, or zero loan-to-value, there is a trade-off relationship between house prices and house quantity demanded. As long as the loan-to-value is positive, house prices are positively related to house quantity demanded.

Equation (13) implies the transmission mechanism of house prices to macroeconomic fluctuations. Suppose house prices rise. Overall, a rise in house prices increases borrowing capacity and net worth. Housing and consumption are boosted because of heightened collateral values and net worth. In turn, higher housing demand further increases house prices. The change in housing net worth is associated with a high leverage effect, measured in the loan-to-value, which makes net worth much higher relative to a required down payment. Indeed, leverage plays an amplifying role in net worth. ${ }^{10}$ The converse holds when there is a decline in house prices. As the leverage ratio rises, it decreases net worth. Households may default due to negative equity. Housing and consumption can shrink because of tighter borrowing constraints, as a fall in collateral values, and net worth, further depresses housing and consumption. Therefore, changes in house prices amplify fluctuations in macroeconomic variables.

\subsection{Entrepreneurs}

The Entrepreneurs derive utility only from consumption. They produce intermediate goods according to the following constant return to scale (CRS) Cobb-Douglas production function with labor, housing and capital as inputs, which can be written as

$$
Y_{t}=Z_{t}\left(K_{t-1}^{v} H_{t-1}^{1-v}\right)^{\mu}\left(N_{1, t}^{\alpha} N_{2, t}^{(1-\alpha)}\right)^{(1-\mu)}
$$

\footnotetext{
10 "The usual notion that a higher land price, $q_{t}$, reduces the farmers demand is more than offset by the facts that (i) they can borrow more when $q_{t}+1$ is higher, and (ii) their net worth increases as $q_{t}$ rises" Kiyotaki and Moore (1997)
} 
where $Y_{t}$ denotes output and $Z_{t}$ represents productivity in period t. $K_{t-1}$ and $H_{t-1}$ denote capital and housing in period t-1, respectively. Furthermore, $K_{t-1}$ and $H_{t-1}$ are initial endowments to entrepreneurs. The shock to $Z_{t}$ follows the stochastic process:

$$
\ln Z_{t}=\left(1-\rho_{z}\right) \ln \bar{Z}+\rho_{z} \ln Z_{t-1}+\varepsilon_{Z, t},
$$

where $\bar{Z}>0, \rho_{Z} \in(-1,1)$ measures the persistence of the shock and $\varepsilon_{Z, t}$ is a white noise process with mean zero and variance $\sigma_{Z}^{2}$. Capital accumulation follows

$$
K_{t}=\left(1-\delta_{K e}\right) K_{t-1}+I_{K t}-\frac{\xi}{2} \frac{\left(K_{t}-K_{t-1}\right)^{2}}{K_{t-1}}
$$

where $I_{k t}$ denotes investment of capital. The parameter $\xi$ denotes convex adjustment parameter. Capital depreciates at the rate $\delta_{K e}$. Housing accumulation follows

$$
H_{e t}=q_{t} H_{e t-1}+I_{H e t}-\varphi_{e} q_{t} H_{e t-1},
$$

where $I_{H e t}$ denotes investment of houses. Housing transactions are associated with the transaction costs like realtor fees, $\varphi_{e} q_{t} H_{e t-1}$, which are paid to unconstrained households. The utility function, budget constraint and borrowing constraint of entrepreneurs can be represented by the utility maximization problem as follows:

$$
\max _{\left\{C_{e t}, b_{e t}, I_{t}, K_{t}, H_{t}, N_{1, t}, N_{2, t}\right\}_{t=0}^{\infty}} E_{0} \sum_{t=0}^{\infty} \gamma^{t} \ln C_{e t},
$$

subject to

$$
\frac{Y_{t}}{X_{t}}+b_{e t}=C_{e t}+\frac{R_{t-1}}{\pi_{t}} b_{e t-1}+w_{1, t} N_{1, t}+w_{2, t} N_{2, t}+I_{k t}+I_{H e t}+\xi_{K t}+\xi_{H e t},
$$

where

$$
\begin{aligned}
& I_{K t}=K_{t}-(1-\delta) K_{t-1}, \xi_{K t}=\frac{\psi_{K}}{2 \delta}\left(\frac{I_{K t}}{K_{t-1}}-\delta\right)^{2} K_{t-1}, I_{H e t}=\left\{H_{e t}-H_{e t-1}\right\} q_{t}, \\
& \xi_{H e t}=\varphi_{e} q_{t} H_{e t-1}
\end{aligned}
$$

and

$$
R_{t} b_{e t} \leq m_{e} E_{t}\left(q_{t+1} \pi_{t+1} H_{e t}\right)
$$


There is a proportional housing transaction costs parameter, $\varphi_{e}$, in the budget constraint. Finally, $m_{e}$ is the constant parameter of the loan to value ratio to entrepreneurs.

\subsection{Retailers}

Retailers as in Iacoviello (2005), which follows Bernanke, Gertler and Gilchrist (1999) take the same firms. Retailers produce a continuum of differentiated final goods modeled under monopolistic competition. Since retailers have market power, profits are assumed to be paid to unconstrained households. The retailers' supply curve implies a Phillips curve, determined by an optimal pricing equation. Retail prices are sticky, and the probability of any retailers being able to adjust its nominal prices is $1-\theta$. The retailers purchase intermediate goods from entrepreneurs with the price of $P_{t}^{\text {inter }}$ and sell final goods to households with the price, $P_{g}$, where the goods are differentiated on a unit interval. Final goods are $Y_{t}(G)=\left(\int_{0}^{1} Y_{t}(g)^{(\xi-1) / \xi} d g\right)^{\frac{\xi}{\xi-1}}$ with $\xi>1$. The solution to the firms' cost minimization problem gives a demand function for intermediate goods and a price index, $P_{t}=\left(\int_{0}^{1} P_{t}^{\text {inter }}(g)^{1-\xi} d g\right)^{\frac{1}{1-\xi}}$. Profit maximization by each retail firm implies that the optimal price of final goods, $\widehat{P}_{t}(g)$, satisfies $\sum_{i=0}^{\infty} \theta^{i} E_{t}\left(\beta \frac{C_{1, t}}{C_{1, t+i}}\left(\frac{\widehat{P}_{t}(g)}{P_{t+i}}-\frac{X_{t}}{X_{t+i}}\right) \widehat{Y}_{t+i}(g)\right)=0$, where $X_{t}$ is the markup. The aggregate price index is $P_{t}=\left(\theta P_{t-1}^{\varepsilon}+(1-\theta) \widehat{P}_{t}^{1-\xi}\right)^{\frac{1}{1-\xi}}$. From the optimization of retailers, the aggregate supply curve can be derived as $\hat{\pi}_{t}=$ $\beta \hat{\pi}_{t+1}-k \hat{X}_{t}+\hat{\varepsilon}_{u, t}$, where $k=\frac{(1-\theta)(1-\beta \theta)}{\theta}$.

\subsection{The Central Bank}

The central bank is assumed to follow a Taylor Rule taking the nominal interest rate as the instrument for monetary policy:

$$
R_{t}=\left(R_{t-1}\right)^{\gamma_{R}}\left(\pi_{t-1}^{1+\gamma_{\pi}}\left(\frac{Y_{t-1}}{Y_{t}}\right)^{\gamma_{y}} q_{t-1}^{\gamma_{q}}\right)^{1-\gamma_{R}} \varepsilon_{R, t}
$$

\subsection{Equilibrium}

The dynamic stochastic equilibrium for given $H_{e, 0}, H_{1,0}, H_{2,0}, b_{e, 0}, b_{1,0}$ and $b_{2,0}$ is a sequence of allocations, $\left\{Y_{t}, C_{e, t}, C_{1, t}, C_{2, t}, H_{e, t}, H_{1, t}, H_{2, t}, b_{e, t}, b_{1 t}, b_{2 t}, N_{1, t}, N_{2, t}\right\}_{t=0}^{\infty}$ and a sequence of prices, $\left\{w_{1 t}, w_{2 t}, R_{t}, q_{t}, P_{t}, \widehat{P}_{t}, \lambda_{t}\right\}_{t=0}^{\infty}$, which satisfy the budget constraints, 
borrowing constraints and first order conditions for each economy. For the markets to clear, the bond market for $b_{t}$, goods market for $Y_{t}$ and the house market for $H_{e t}, H_{1 t}$ and $H_{2 t}$ should meet the following conditions:

(a) $N_{1 t}=N_{2 t}$

(b) $H_{e, t}+H_{1, t}+H_{2, t}=1$,

(c) $C_{e, t}+C_{1, t}+C_{2, t}+I_{t}=Y_{t}$,

(d) $I_{t}=I_{K t}+I_{H e t}+I_{H 1 t}+I_{H 2 t}$,

(e) $s_{t}=\varphi_{e} q_{t} H_{e t-1}+\varphi_{1} q_{t} H_{1 t-1}+\varphi_{2} q_{t} H_{2 t-1}$,

(f) $b_{t}+b_{1 t}+b_{2 t}=0$

Wages are different across households and based on their productivity. In the steady state, unconstrained households receive wage bills of $w_{1} N_{1}=\alpha(1-\mu-v) Y$, while constrained households receive a wage bill of $\left.w_{2} N_{2}=(1-\alpha)\right)(1-\mu-v) Y .{ }^{11}$

\subsection{Solution Method}

The solution of the dynamic model involves non-linear equations and identity equations. The steady state values of the state variables are recovered from a nonlinear system of equations. This step uses the Broyden method for solving systems of nonlinear equations. After obtaining steady state values, the model is loglinearized. All derivatives of the first order conditions are automatically calculated using the Jacobian command in Matlab. Finally, the Uhlig toolkit is used to solve the linear system of stochastic difference equations.

\section{Calibration and Estimation}

\subsection{Calibration}

The steady state value for labor hours for both unconstrained households and constrained households is 0.33 . The housing preference parameter, $j$, is set to 0.21 in order to match the share of GDP. Following Luengo-Prado and Sorensen (2006), and Li, Liu and Yao (2008), and Stokey (2007), the transaction costs for constrained households is 5 percent. This is consistent with the data from the Department of Justice in 2009. The benchmark model assumes a lower level of 3 percent as the transaction cost of entrepreneurs. In the

\footnotetext{
${ }^{11}$ All equations are related to the steady state and log-linearization.
} 
sensitivity analysis, 6 percent for entrepreneurs is also applied. Either 3 percent or 6 percent can be applied without changing results. Also recall that unconstrained households, as realtors, pay no transaction costs.

The discount factors for unconstrained households, constrained households and entrepreneurs, the share of housing to consumption, the parameters of production across capital and housing, the probability of the price adjustment and the depreciation rate for housing are the same values as in Iacoviello (2005).

Table 1: Calibration

\begin{tabular}{|c|c|c|}
\hline Parameter & Value & Data to Match \\
\hline \hline$\beta, \gamma, \beta_{2}$ & $0.99,0.98,0.97$ & subjective discount rate \\
\hline$j$ & 0.21 & share of housing to consumption \\
\hline$\varphi_{1}, \varphi_{e}, \varphi_{2}$ & $0.0,0.03,0.05$ & housing transaction costs \\
\hline$\eta$ & 1.01 & elasticity of labor \\
\hline$\delta$ & 0 & depreciation of housing \\
\hline$\mu, \nu$ & $0.3,0.03$ & share of capital and housing \\
\hline$X$ & 1.05 & markup \\
\hline$\theta$ & 0.75 & probability of the fixed price \\
\hline
\end{tabular}

\subsection{Estimation}

\subsubsection{Monetary Policy}

For monetary policy, I assume that the nominal interest rate responds to past inflation and past output through the following Taylor Rule, which is a log-linearization of Equation (19):

$$
\hat{R}_{t}=\alpha_{R} \hat{R}_{t-1}+\left(1-\alpha_{R}\right)\left(\left(1+\alpha_{\pi}\right) \hat{\pi}_{t-1}+\alpha_{Y} \hat{Y}_{t-1}\right)+\hat{\varepsilon}_{R, t} .
$$

I estimate the parameters of the Taylor Rule using the OLS method.

Table 2: Taylor Rule: Estimation using OLS

\begin{tabular}{cccc}
\hline Variable & Coefficient & Std.Error & t-Statistic \\
\hline \hline$\hat{R}_{t-1}$ & 0.84 & 0.035 & 23.63 \\
$\hat{Y}_{t-1}$ & 0.011 & 0.008 & 1.35 \\
$\hat{\pi}_{t-1}$ & 0.264 & 0.06 & 4.19 \\
Constant & 0.024 & 0.045 & 0.5 \\
\hline
\end{tabular}


Monetary policy makers respond to past inflation and output through a lagged interest rate. The coefficients are estimated: $\widehat{R}_{t}=\underset{(0.03)}{0.84} \widehat{R}_{t-1}+\underset{(0.06)}{0.26} \widehat{\pi}_{t-1}+\underset{(0.008)}{0.011} \widehat{y}_{t-1} \cdot{ }^{12}$ Hence Equation (20) can be written as

$$
\widehat{R}_{t}=\underset{(0.03)}{0.84} \widehat{R}_{t-1}+0.16\left(\underset{(0.06)}{1.5} \widehat{\pi}_{t-1}+\underset{(0.008)}{0.069} \widehat{y}_{t-1}\right) .
$$

\subsubsection{Estimation}

The crucial parameter for the model is the elasticity of substitution of housing for consumption. Here, I discuss two estimates of this parameter. The first involves a cointegration method. The second uses minimum distance estimation between model and data impulse responses.

Using NIPA data, I estimate this elasticity of intratemporal substitution, $\varepsilon$, to be 0.19 (Song (2009)) using a co-integrating method. I find a significant estimate of this elasticity of substitution, $\varepsilon$, to be 0.19 . The key point for this significance is the time period of the data. The sample period is important because different sample periods provide different significance of statistical analysis. The sample period of NIPA data is from 1970 through 2009, which is different from the samples from 1947 to 2001 as in Piazzesi et al. (2007). The relative price is the ratio of the price index of housing services to the price index of nondurable consumption. I use co-integration approach to parameter estimation. The complementarity, or the elasticity of intratemporal substitution between housing and consumption is estimated at 0.19, 0.19 and 0.18 through DOLS, CCR and FMOLS, respectively. Piazzesi et al. (2005) also use NIPA data to estimate the parameter of the elasticity of substitution using co-integration method, which, however, is not significant statistically. The data in their paper is used in two different categories: long sample periods (19362001) and post-war sample periods (1947-2001). The results are different based on the the beginning period of 1936 and 1947. However, the periods from 1970 through 2009 as in Song (2009) significantly provide co-integration trends. This finding is consistent with the results of Flavin and Nakagawa (2004) who apply GMM to the PSID. They estimate the EIS at 0.13 .

For robustness, instead of using co-integrating method through which I identified complementarity, I broadly follow the methodology of Iacoviello (2005) in that I use minimum

\footnotetext{
${ }^{12}$ Following Equation (2), the coefficients are transformed into $\left(1-\alpha_{R}\right)\left(1+\alpha_{\pi}\right)=0.26 \rightarrow \alpha_{\pi}=\frac{0.26}{\left(1-\alpha_{R}\right)}-$ $1,\left(1-\alpha_{R}\right) \alpha_{Y}=0.011 \rightarrow \alpha_{Y}=\frac{0.011}{\left(1-\alpha_{R}\right)}$.
} 
distance estimation using macro data from 1970:Q1 to 2008:Q4, such as the Federal Fund Rate (fedfunds), inflation ( GDP deflator), house prices (CMHPI), and real GDP (GDPC1). However, this estimation still differs from Iacoviello (2005) in substantive ways. First, I use a different time period. Second, I add two more structural parameters: 1) the elasticity of intratemporal substitution, $\varepsilon$, and 2) risk aversion, $\varsigma$.

The EIS, $\varepsilon$, is estimated at 0.592 with a standard error of 0.053 , thus providing strong support of preferences over housing and consumption for nonseparability and complementarity. I estimate the empirical impulse responses using the VAR method. The Choleski ordering is the Fed Fund Rate, inflation, house prices and the output gap. The distance function is $f(b)=I R F_{M}(b)-I R F_{D}$, where $I R F_{M}(b)$ is the impulse responses obtained from the model, $I R F_{D}$ is the data responses from the VAR, and $b$ is the vector of parameters $\left(\varepsilon, \sigma, \sigma_{u}, \sigma_{j}, \sigma_{a}, r_{u}, r_{j}, r_{a}, a, m_{1}, m_{2}\right)$. There exist solutions to the minimization of $J_{t}(b)=\underset{b}{\operatorname{II}}\left[\underset{(314 \times 1)}{f}(b)^{T} \underset{(314 \times 314)}{\Phi} \underset{(314 \times 1)}{f}(b)\right]$, where $\Phi=\underset{314 \times 314}{W} \underset{314 \times 314}{\Omega^{-1}}$, where $\Omega^{-1}$ is the inverse matrix of the sample variance of the IRFs.

Table 3: Estimation

\begin{tabular}{|c|c|c|c|c|c|}
\hline Parameter & Value & STD.e & Parameter & Value & STD.e \\
\hline$\varepsilon=$ elasticity of substitution & 0.592 & 0.053 & $\phi_{\pi}=$ autoregressive $_{\pi}$ & 0.629 & 0.043 \\
\hline$\varsigma=$ curvature & 2.317 & 0.357 & $\phi_{\mathrm{J}}=$ autoregressive $_{j}$ & 0.885 & 0.017 \\
\hline$a=$ share of wage & 0.553 & 0.046 & $\phi_{a}=$ autoregressive $_{a}$ & 0.177 & 0.1 \\
\hline$m_{e}=$ loan - to - value $_{e}$ & 0.412 & 0.066 & $\sigma_{A}=s t d e v_{a}$ & 9.195 & 3.5 \\
\hline$m_{2}=$ loan - to - value $_{2}$ & 0.861 & 0.02 & $\sigma_{j}=s t d e v_{j}$ & 0.021 & 1.64 \\
\hline$\sigma_{R}=s t d e v_{R}$ & 0.24 & 0.009 & $\sigma_{\pi}=s t d e v_{\pi}$ & 0.154 & 0.024 \\
\hline
\end{tabular}

\section{$5 \quad$ Results}

\subsection{The Issue of Separable Preferences with housing transaction costs}

In Figure 3, I examine the effect of housing transaction costs on aggregate consumption to an exogenous positive house price shock of 1 percent under separable preferences. A persistent change in house prices is generated by a common, exogenous shock to $j$ that affects all households. In this first example, I set $\varepsilon=1$ to eliminate complementarity between housing and consumption. Thus utility is separable in housing and non-housing consumption. Panel (A) shows results when there are no transaction costs. In contrast, 
Panel (B) introduces transaction costs. The triangled, squared, and circled lines are the impulse responses of aggregate consumption to the increase in house prices. The house loan-to-value ratios of those three lines for entrepreneurs and constrained households are set to (0.1 percent, 0.1 percent), (45 percent, 30 percent) and (89 percent, and 55 percent), respectively.

Figure 3: Separability and Proportional Transaction Costs
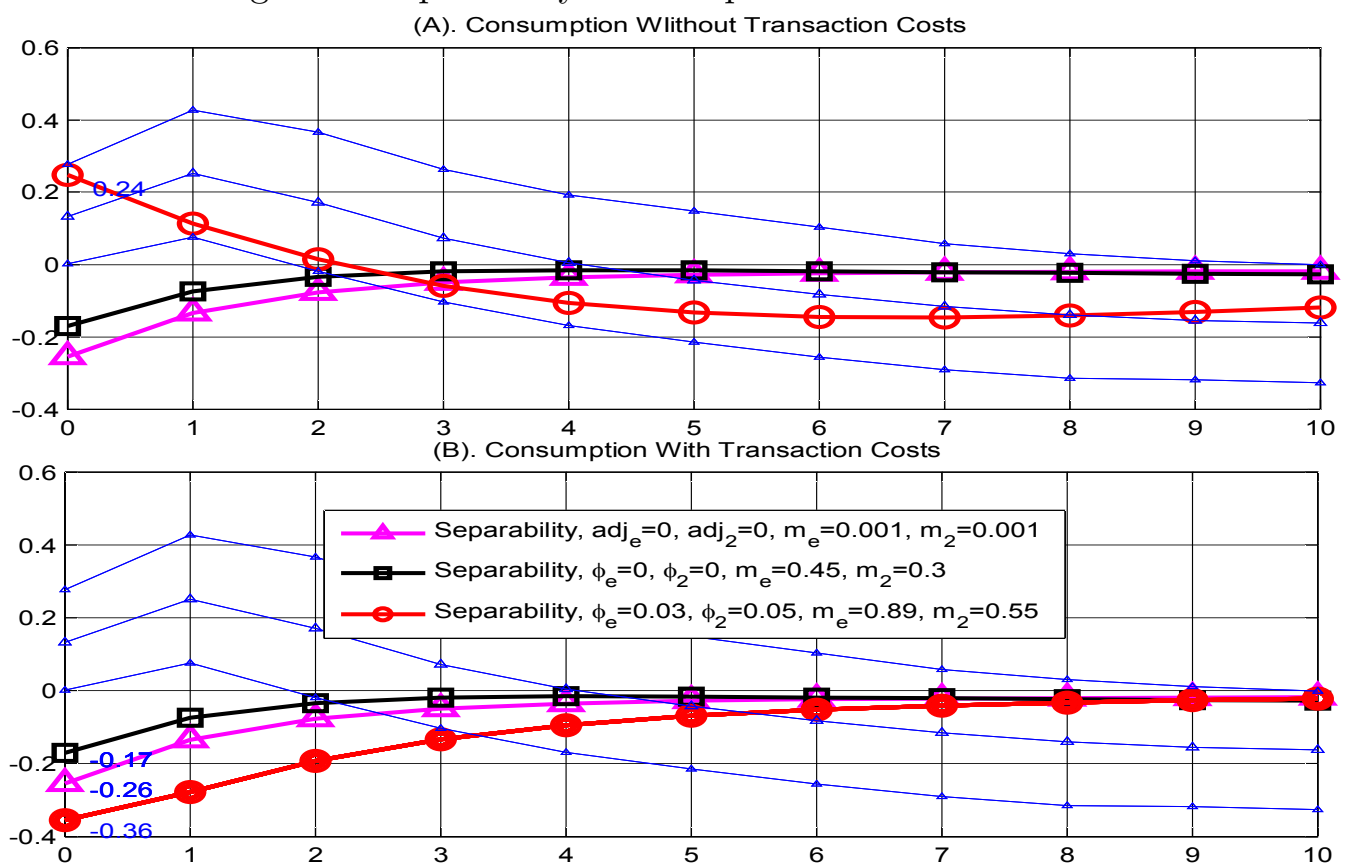

Panel (A) is a replication of Iacoviello (2005) with his log utility function. As in his paper, there are no housing transaction costs. With loan-to-value ratios of 89 percent for entrepreneurs and 55 percent of constrained households, aggregate consumption rises by 0.24 percent after an 1 percent increase in house prices. In this consumption response, the loan-to-value ratios are critical factors, which make the model successful, so that the response matches the data within the 90 percent confidence intervals. The other loanto-value ratios do not induce effective co-movement between housing and consumption. Hence, the co-movement between house prices and consumption depends on the loan-tovalue ratio.

In order to see the effects of proportional housing transaction costs on aggregate con- 
sumption, I compare the circled line in Panel (A) with that in Panel (B). The circled line in Panel (B) shows the consumption response with the presence of transaction costs of 5 percent and 3 percent for constrained households and entrepreneurs respectively. ${ }^{13}$

Critically, once we introduce empirically plausible levels of transaction costs, the positive consumption response to a rise in house prices disappears. Transaction costs dominate and dampen the effects of loan-to-value ratios so that aggregate consumption no longer increases following a rise in house prices. The aggregate consumption response is severely affected by transaction costs. In other words, housing transaction costs nullify the effect of loan-to-value ratios on consumption. Hence, separable utility function between housing and consumption in this model, cannot generate a co-movement between house prices and consumption when housing transactions costs are introduced. ${ }^{14}$

\subsection{Complementarity between Housing and Consumption}

Figure 4 resolves the problem caused by housing transaction costs in Figure 3. The solution relies on the introduction of nonseparable preferences over housing and consumption. Since the extent of non-separability of preferences is jointly determined by the elasticity of intratemporal substitution, $\varepsilon$, and curvature, $\varsigma$, the parameters are now jointly estimated. The estimates of $\varepsilon$ and $\varsigma$ are 0.59 and 2.3, respectively. As before, a rise in house prices is generated by a shock to housing demand, $j$, common across households. The house loan-to-value ratios, for entrepreneurs and constrained households, are set to 41 percent and 86 percent, respectively.

Panel (A) shows that complementarity induces a positive aggregate consumption response following a positive house price shock of 1 percent. When housing transaction costs are set to 5 percent and 3 percent for constrained households and entrepreneurs, respectively, the consumption response rises to 0.31 percent, which falls within the 90 percent confidence intervals of the data.

Panel (B) examines the sensitivity of my results with respect to housing transaction costs, fixing the loan-to-value ratios for entrepreneurs and constrained households to 41

\footnotetext{
${ }^{13}$ In the sensitivity, 6 percent is applied.

${ }^{14}$ Empirical impulse responses come from the estimated VAR using the data of federal fund rate, real house prices, real personal consumption expenditures, real GDP and inflation. Inflation is the change in GDP deflator. All variables are already de-trended by BP filter and taken by logarithm. The data, data transformation, and the order in the VAR are the same as in Iacoviello (2005).
} 
percent and 86 percent, respectively.

Figure 4: Complementarity with Transaction Costs and Loan-to-Values (A). Agg.Consumption: $\phi_{\mathrm{e}}=0.03 \phi_{2}=0.05 \mathrm{~m}_{\mathrm{e}}=041 \mathrm{~m}_{2}=0.86$

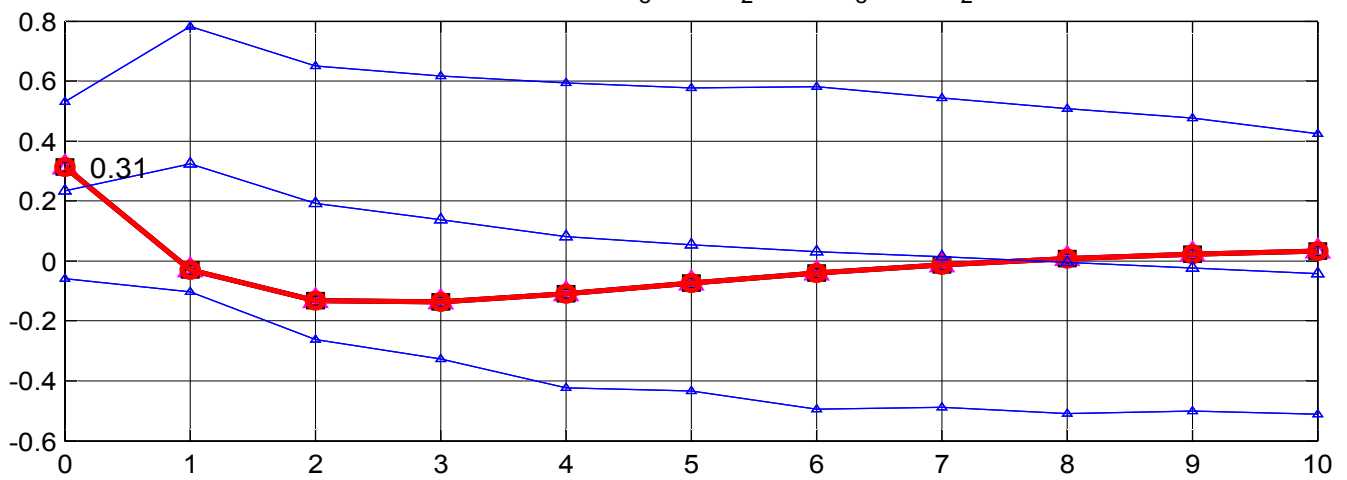

(B). Consumption using Different values of Adjustment Costs

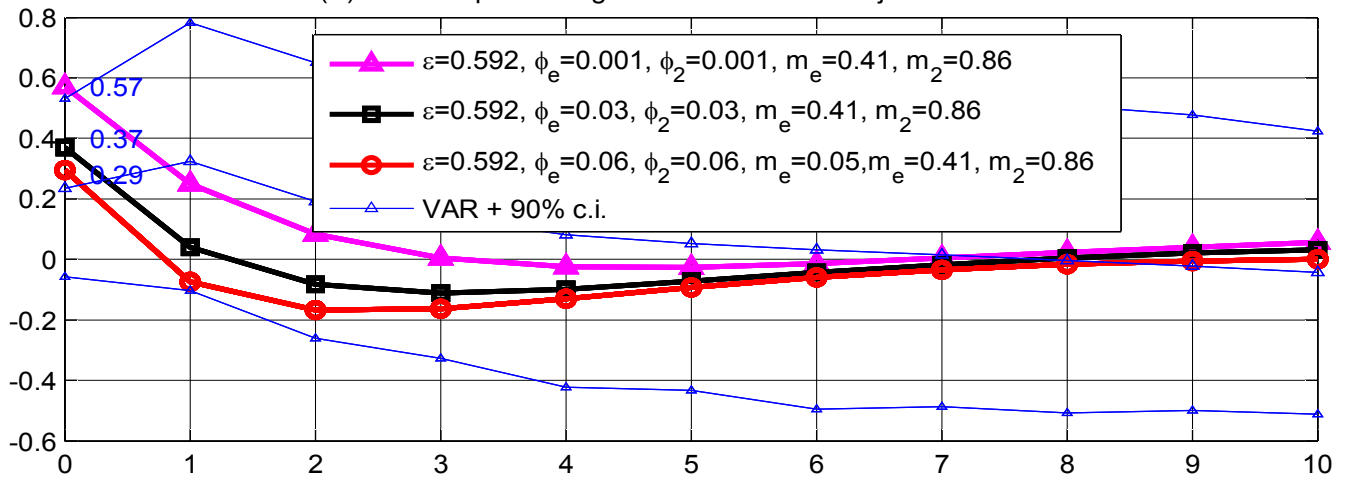

As transaction costs increase to 6 percent for all agents, the aggregate consumption response at the impact date falls to 0.29 percent. Consumption soars when transaction costs are close to zero with the consumption response climbing to 0.57 percent, which causes the response to lie outside the 90 percent confidence intervals. In other words, when there are no transaction costs, the consumption response becomes implausibly large. ${ }^{15}$

\footnotetext{
${ }^{15}$ The confidence intervals come from the VAR, estimated from the data for federal fund rate, inflation, house prices and output from 1970 Q1 to 2008 Q4. These series are the same as in Iacoviello (2005), but for different time periods.
} 


\subsection{Consumption Across Households}

In Figure 5 I investigate how an 1 percent increase in house prices affects consumption of different households as transaction costs vary. There are two types of households: constrained and unconstrained. Aggregate consumption data on these types of households are taken from Consumer Expenditure Surveys from 1984:Q1 to 2008:Q4. Constrained households are assumed to be young households (below 35 years old) whose housing purchase is typically highly leveraged, as in Flavin and Yamashita (2002). On the other hand, unconstrained households are assumed to be relatively old households (over 35 years old). The model's parameters for complementarity and loan to value ratios for entrepreneurs and constrained households are set to $0.59,0.41$ and 0.86 , respectively.

Figure 5: Consumption across Households

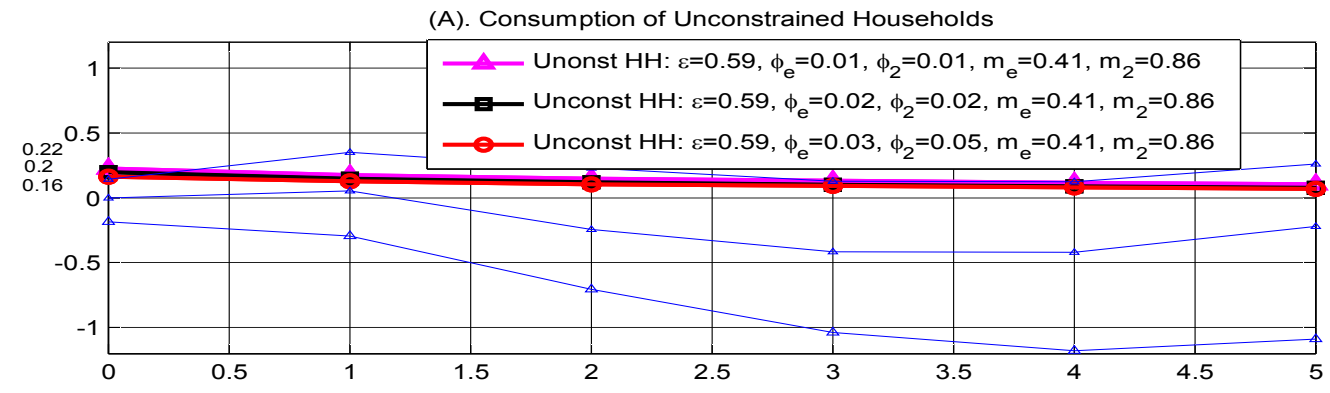

(B). Consumption of Constrained Households

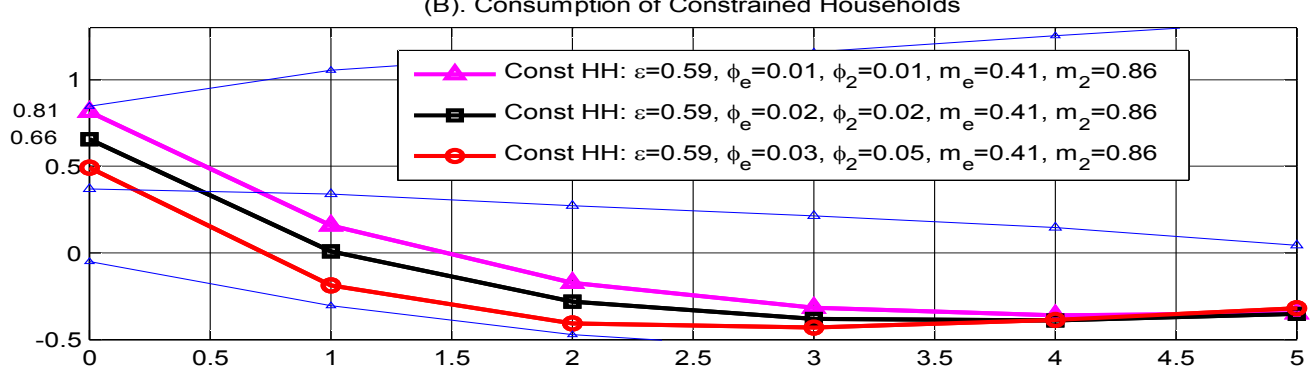

When experiencing an one percent exogenous increase in house prices, the gains in house prices are not equally distributed across the heterogeneous households. In other words, the two types of households react differently to a shock in house prices. Generally, as transaction costs fall, the consumption response is likely to rise. A key result of the model is that constrained households are more likely to be responsive to a change in house 
prices than unconstrained households.

Panel (A) shows the consumption response of unconstrained households. Initially, unconstrained households increase consumption by around 0.2 percent. Moreover, the slope of their consumption response is generally flat. Interestingly, their consumption response does negligibly vary when facing different transaction costs. Therefore, transaction costs do not significantly affect the consumption responses of unconstrained households. The consumption response for constrained households is illustrated in Panel (B). Overall, constrained households are substantially more responsive to the increase in house prices than unconstrained households. In fact, as transaction costs decrease, the consumption response rises to 0.5 percent, 0.66 percent and 0.81 percent. Contrary to unconstrained households, transaction costs are a significant factor for credit-constrained households.

The implication is as follows. Suppose there is a rise in house prices. The marginal propensity of consumption (MPC) out of gains in house prices for constrained households is larger than that for unconstrained households. This difference in the MPC across households leads to a change in overall aggregate consumption. Constrained households are likely to use their increase in housing collateral value to finance an increase in consumption that exceeds the house price increase.

\subsection{The Effect of Elasticity of Intertemporal substitution on Consump- tion across Households}

Figure 6 illustrates how an 1 percent increase in house prices affect consumption across heterogeneous households with respect to the elasticity of intertemporal substitution, $\sigma=1 / \varsigma$. The consumption response to an 1 percent increase in house prices is displayed with respect to $\varsigma$. Transaction costs and loan-to-values for entrepreneurs and constrained households are set to 3 percent, 5 percent, 41 percent and 86 percent, respectively. I applied the parameter values of 2.3, 6 and 10 for $\varsigma$ in order to consider the case when risk aversion is normal, high and very high for unconstrained households (Panel A) and for constrained households (Panel B). The EIS is held fixed at 0.59 .

Panel (A) displays the effect of risk aversion on consumption of unconstrained households. The consumption responses facing different values of risk aversion are negligibly different. Risk aversion does not significantly affect the consumption decision for unconstrained households.

Panel (B) displays the effect of risk aversion on consumption of constrained households. 
Figure 6: Consumption sensitivity facing different risk aversion, $\sigma$

(A). Consumption of Unconstrained Households

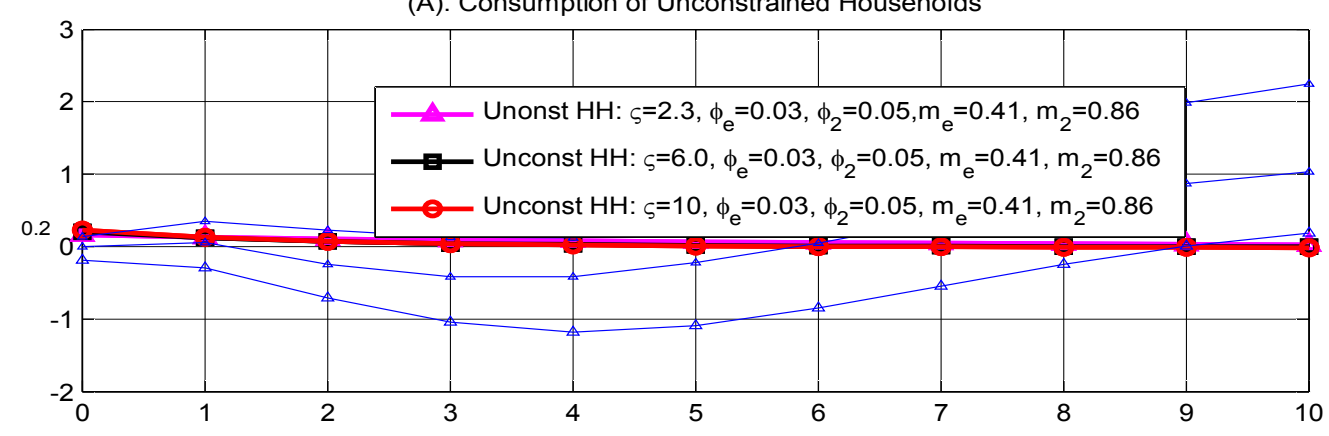

(B). Consumption of Constrained Households

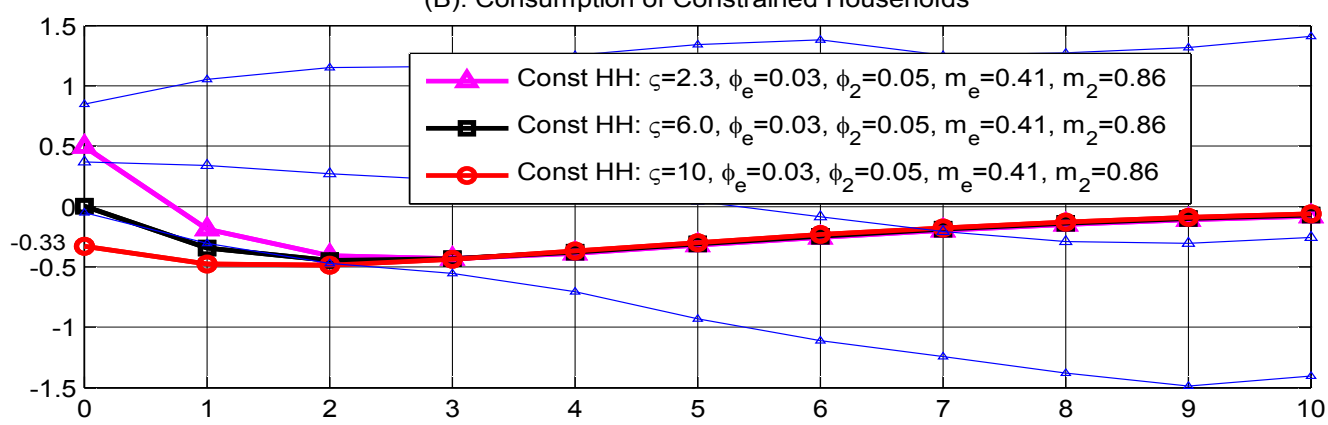

Generally, higher risk aversion induces lower initial consumption. When $\varsigma=10$, the initial rise in the consumption of constrained households seen at lower levels of risk aversion is completely overturned. When risk aversion is 2.3 , the consumption response to an 1 percent rise in house prices is 0.5 percent.

Overall, risk aversion affects consumption decisions of constrained households. Even a positive house price shock can lead to a fall in consumption when risk aversion is high, that is when households are unwilling to substitute consumption inter-temporally. The effect of a low elasticity of intertemproal substitution offsets the positive effect of house prices.

\section{Results for Monetary Policy}

This section studies the effect of interest rate shocks on housing and consumption. My first result illustrates how changes in $\varepsilon$, the intratemporal elasticity of substitution between 
housing and consumption, affects the effective degree of risk aversion across households. This leads to different consumption responses in response to an increase in interest rates. Figure 7 shows a cumulative consumption loss across households after an 1 percent increase in interest rates for benchmark. Panel (A) is the aggregate cumulative consumption response to tighter monetary policy. Aggregate consumption falls to 1.92 percent initially. Panel (B) shows that an increase in interest rates decreases consumption for both constrained and unconstrained households. However, this decrease is larger for constrained households.

Figure 7: Cumulative Consumption Loss responding to a Rise in the Interest Rate
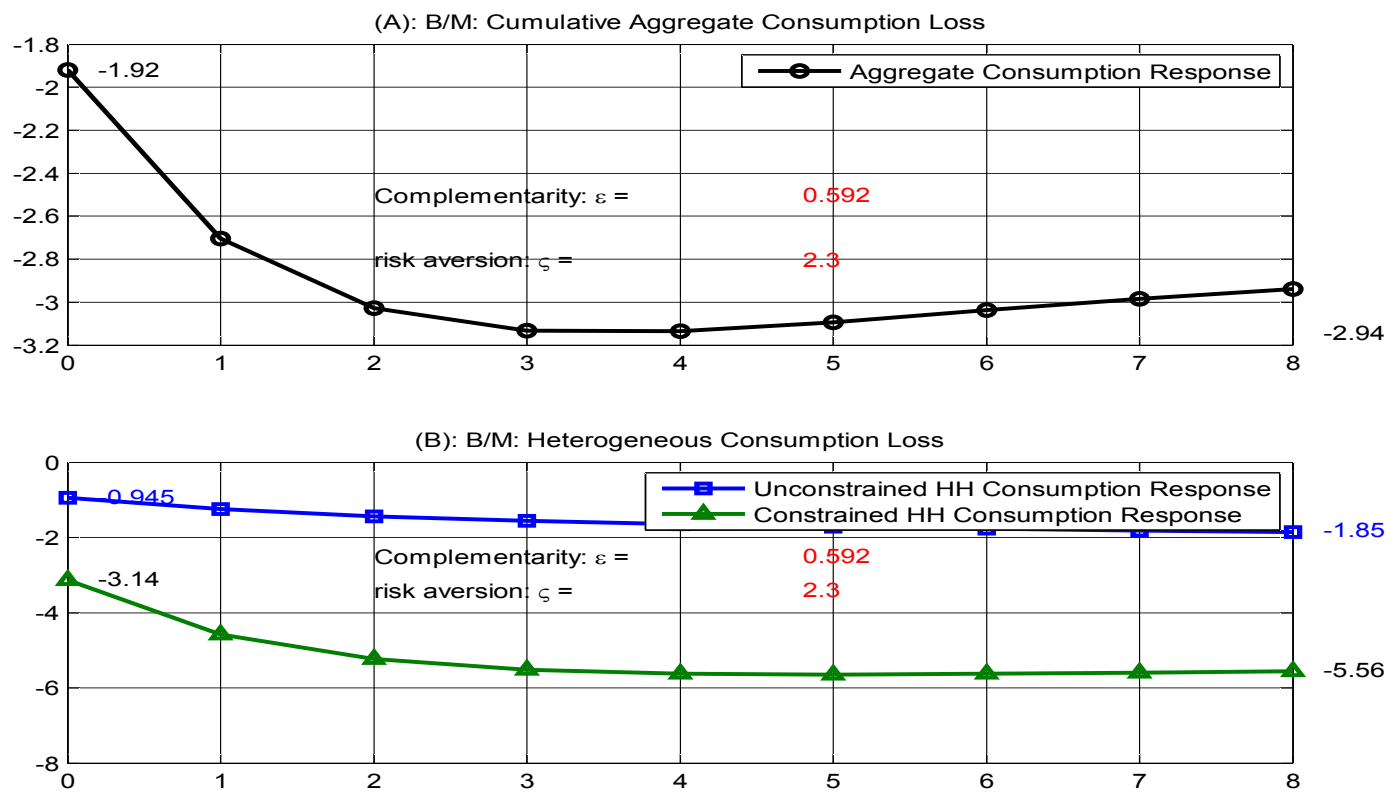

Figure 8 shows the case when the degree of complementarity, $\varepsilon$, is stronger (lower value and bold lines) than the benchmark. Aggregate consumption further falls in response to the increase in interest rates with the stronger complementarity. For constrained households, the increase in the interest rate with the stronger complementarity induces them to significantly decrease consumption. Since they are constrained by collateral and an increase in the interest rate reduces the values of their collateral, consumption falls by more with stronger complementarity. A negative shock induces them to be more risk averse, so that their consumption loss further decreases to 5.38 percent compared to the benchmark. The 
stronger complementarity effect on consumption of unconstrained households is different from that of constrained households. Unconstrained households are not significantly sensitive to an increase in interest rates because they are not constrained by housing collateral, and they can initially benefit from more interest amount as lenders. Stronger complementarity magnifies the effect of interest rates, so that the gap between two consumption responses across heterogeneous households widens.

Figure 8: Cumulative Consumption Loss responding to a Rise in the Interest Rate
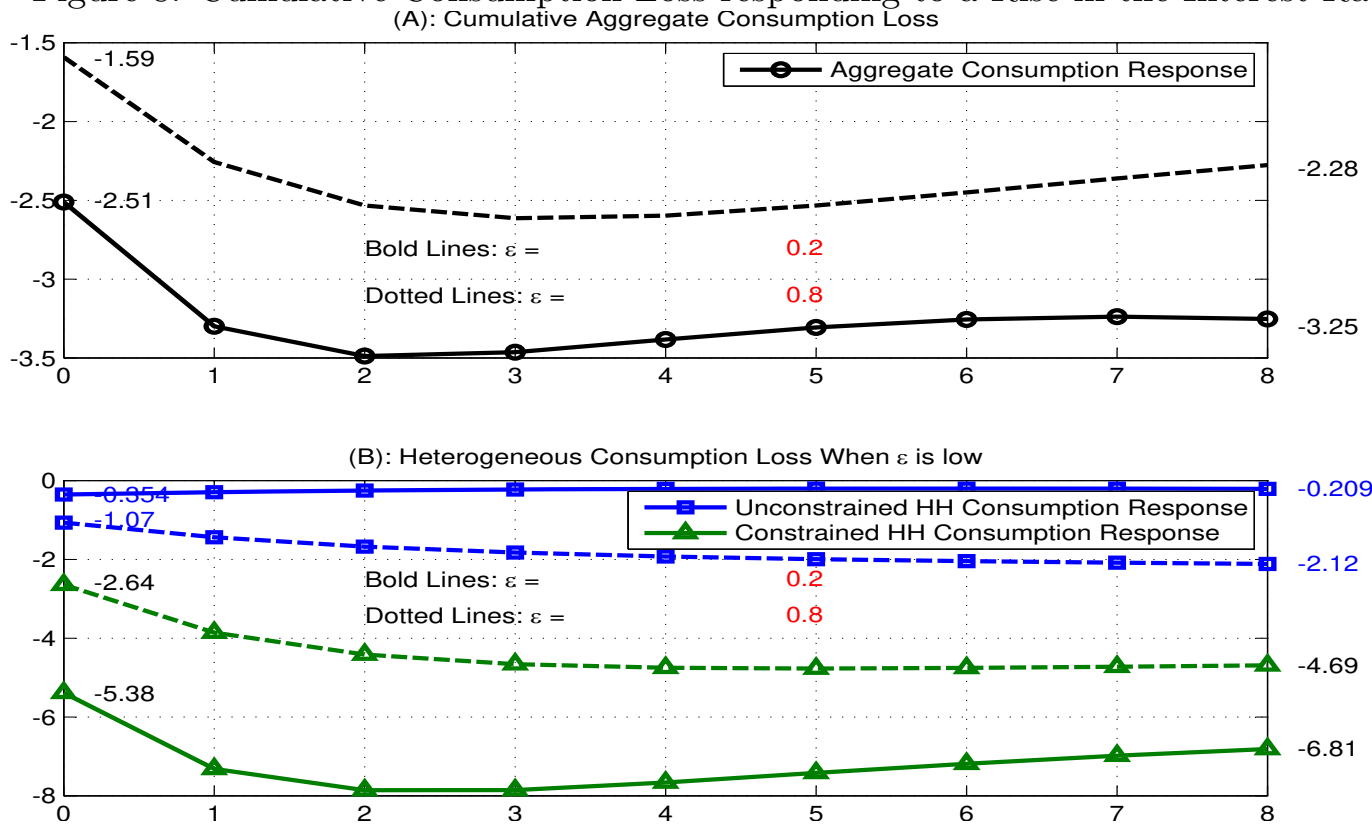

In Figure 8, the dotted lines show the case in which the degree of complementarity, $\varepsilon$, become weaker (higher value) than the benchmark. For constrained households, the precautionary saving motive is not as strong as in the bold lines. The negative interest effect on consumption for constrained households becomes smaller with weaker complementarity. The higher degree of substitutability within a period of time make constrained households less effectively risk averse, so that they decrease consumption by less compared to the benchmark. The aggregate cumulative consumption loss is only 2.64 percent at impact. Unconstrained households, however, become more sensitive to the increase in the interest rate. Overall, the disparity of consumption across heterogeneous households is lessened.

We now study the effect of different loan-to-value ratios on the sensitivity of the econ- 
omy to monetary policy. Figure 9 shows the effects of annual one percent increase in the interest rate on aggregate consumption. Panel (A) and Panel (B) are the benchmark based on the estimated or calibrated parameter values: curvature, $\varsigma$, and complementarity, $\varepsilon$, are set to 2.3 and 0.592 , respectively. Loan-to-values for entrepreneurs and constrained households are set to 42 percent and 86 percent, respectively. As already seen, a rise in the interest rate serves to significantly decrease house prices and consumption as shown in Panel (A) and Panel (B). The decrease in consumption is larger for constrained households.

Figure 9: Loan-to-Values Facing a Rise in the Interest Rate

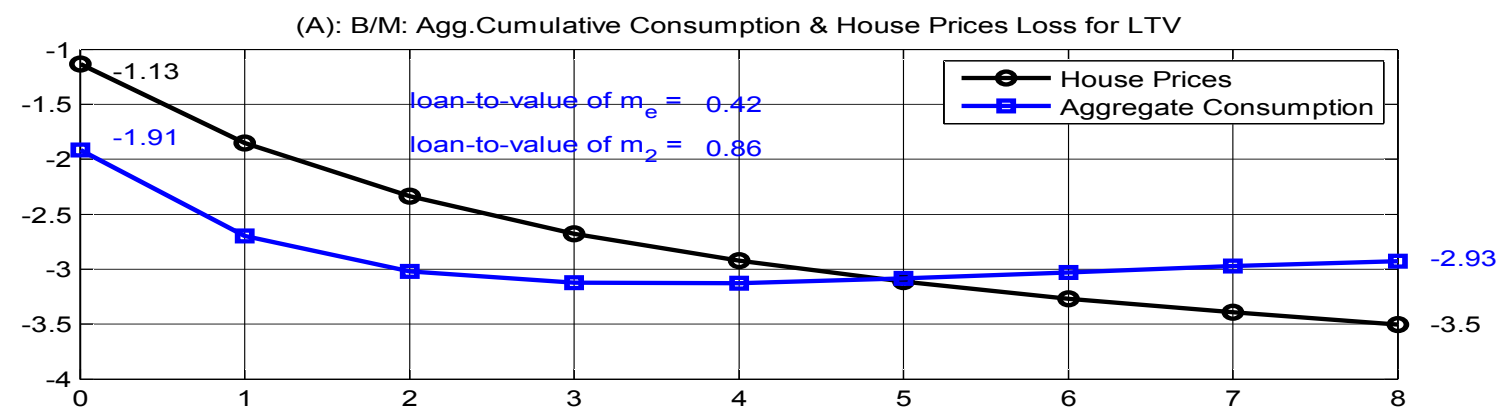

(B): B/M: Consumption Across Households for LTV

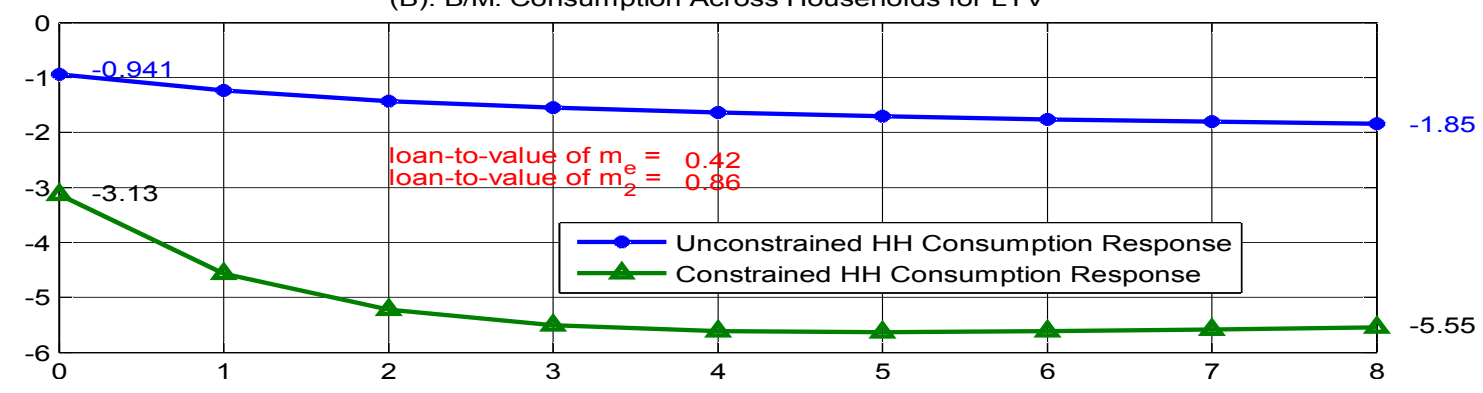

Figure 10 displays the negative effect of loan-to-values on house prices and consumption facing tighter monetary policy. As loan-to-value ratios increase to 80 percent and 91 percent for entrepreneurs and constrained households, house prices and aggregate consumption further decrease. Importantly, higher loan-to-value ratios increase the volatility of house prices caused by changes in monetary policy. Specifically, an 1 percent rise in interest rates now decreases house prices to 1.31 percent at impact. They then reach a 4.59 percent loss in cumulative way. House prices become even more volatile. Furthermore, the increase in the interest rate now leads households to decrease consumption by more. The initial cumulative 
consumption losses across constrained households and unconstrained households is 4.59 percent and 1.02 percent, respectively. This cumulative loss of consumption to an increase in interest rates is significantly larger for constrained households, and the gap between the two impulse responses widens as loan-to-value ratios increase.

Figure 10: Loan-to-Values Facing a Rise in the Interest Rate (A): B/M: Agg.Cumulative Consumption \& House Prices Loss for LTV

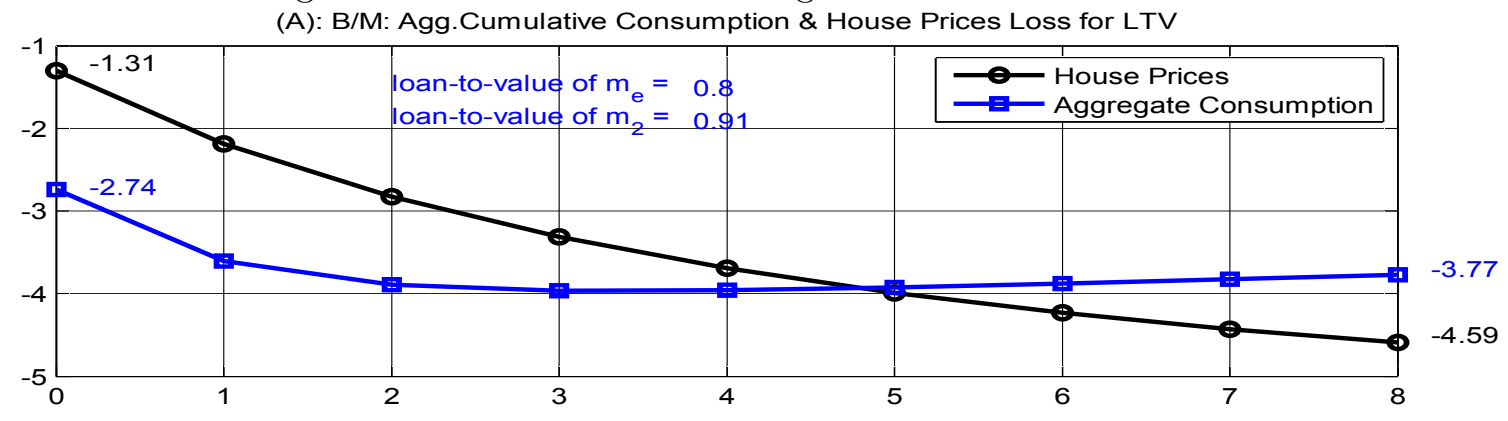

(B): B/M: Consumption Across Households for LTV

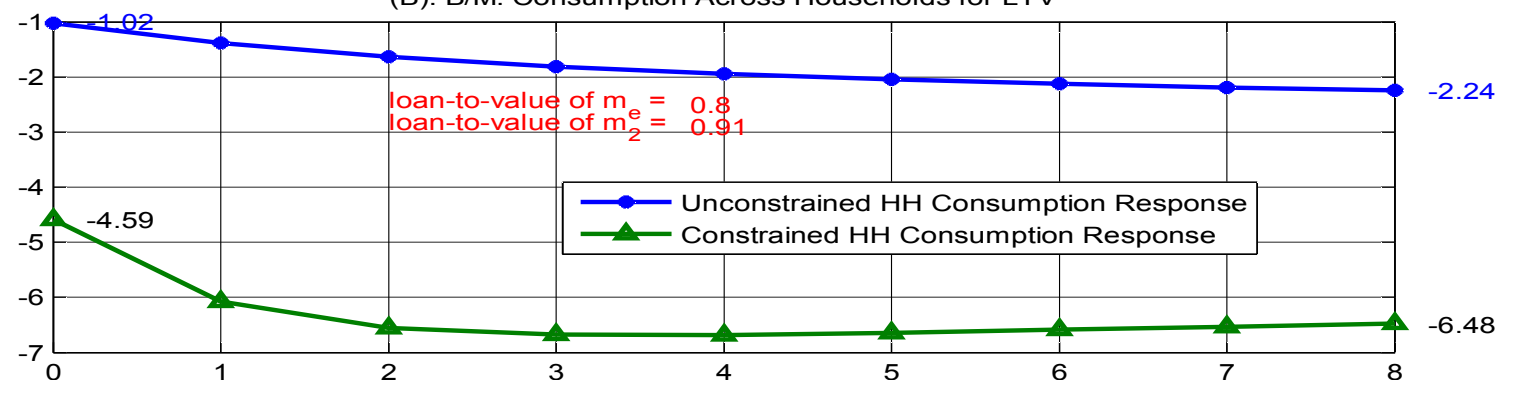

\section{Conclusion}

This paper explores the implications of shocks to housing demand and monetary policy in a model where period utility is nonseparable in housing and non-housing consumption, and where housing sales involve transaction costs. When housing transaction costs are introduced into dynamic stochastic general equilibrium models where period utility is additively separable in housing and consumption, such models fail to reproduce the comovement between these series that is observed in the data. By eliminating the log utility assumption and allowing for complementarity in preferences, I develop a model that can accommodate the realism of housing transaction costs while retaining the co-movement 
between housing and consumption.

My model generates differing elasticities of response across households following aggregate shocks. Following changes in both house prices and interest rates, the consumption response of credit-constrained households is greater than that of unconstrained households. I trace this differing responsiveness in consumption to the house loan-to-value ratios characterizing credit-constrained households. Loan-to-value ratios amplify the effect of changes in interest rates on consumption especially for credit-constrained households. I also find that the differences widen with the degree of complementarity between housing and consumption.

Following a rise in house prices, the net worth of credit-constrained households increases, which boosts their access to credit. This, in turn, allows constrained households to raise their spending on consumption and housing. Moreover the resulting rise in housing demand leads to a further increase in house prices. While transaction costs abate this process somewhat, the fundamental co-movement between housing and consumption persists.

In ongoing research, I am using a related framework to examine the role of financial frictions in determining household consumption. Since down-payments associated with mortgages are determined by banks, house loan-to-value ratios are, to some extent, exogenous for households. Thus, I develop a model where changes in loan-to-value ratios serve as financial shocks and use it to investigate the effect of such shocks on consumption and house prices. In particular, I study how constrained households react to financial innovation that lowered loan-to-value ratios. 


\section{REFERENCES}

[1] Aoki, Kosuke;Proudman, James and Vlieghe Gertjan, "House prices, Consumption, and Monetary Policy: a Financial Accelerator Approach", Journal of Financial Intermediation, 2004, 13, pp. 414-35.

[2] Bernanke, Ben S. and Gertler, Mark. "Inside the Black Box: Credit Channel of Monetary Policy Transmission", Journal of Economic Perspectives, Fall 1995, 9 (4), pp. 27-48.

[3] Campbell, John Y. and Cocco, Joao F., "How do house prices affect consumption? Evidence from micro data", Journal of Monetary Economics, 2006,

[4] Christiano, Lawrence J., Eichenbaum, Martin and Charles Evans, "Nominal Rigidities and the Dynamic Effects of a Shock to Monetary Policy", Journal of Political Economy, 2005, 113(1), pp. 1-46.

[5] Robert B. Couch, "Portfolio Choice with complementarity housing", Working Paper, 2004.

[6] Eberly, Janice C., "Adjustment of Consumers' Durables stocks: Evidence from Autombile Purchases", Journal of Political Economy, June 1994, pp. 403-436.

[7] Iacoviello, Matteo; "House Prices, Borrowing Constraints and Monetary Policy in the Business Cycle", American Economic Review, June 2005, 95 (3), pp. 739-764.

[8] Flavin,Marjorie and Nakagawa Shinobu;"A Model of Housing in the Presence of Adjustment costs: A structural interpretation of habit persistnce", NBER, April 2004.

[9] Flavin,Marjorie and Yamashita Takashi; "Owner Occupied Housing and the Composition of the Household Portfolio", American Economic Review, December 2002.

[10] Grossman,Sanford J. and Laroque, Guy.; "Asset Pricing and Opitmal Protfolio Choice in the Presence of Illiquid Durable Consumption", Econometrica, January 1990, 58(1),pp.2551.

[11] Hanushek, Eric A. and John M. Quigley.; "What is the price elasticity of housing demand?", Review of Economics and Statistics, 1980, 62,pp.449-454.

[12] Kato,Ryo;"A User Guide for Matlab Code for an RBC Model Solution and Simulation", FRB of Philadelphia Working paper, March 2009: No. 09-7.

[13] Kiyotaki,Nobuhiro and Moore,J; "Credit Cycles", Journal of Political Economy , 1997: Vol.105 pp.211-248.

[14] Lam,Pok-sang ; "Irreversibility and Consumer Durables Expenditures", Journal of Monetary Economics, January 1989: Vol.23 pp.135-150.

[15] Li,Wenli, Liu,Haiyong, and You,Rui;"Housing over Time and over the Life Cycle:A 
Structural Estimation", Working paper, ISBN: 0-262-13420-9.

[16] Luengo-Prado,Maria Jose, and Sorensen,Bent E. "Measuring intertemporal substitution: the role of durable goods". Journal The Review of Economics and Statistics, 2008, Vol 90, 65-80.

[17] Miranda,Mario and Fackler, Paul;"Applied Computational Economics and Financeo", MIP Press, ISBN: 0-262-13420-9.

[18] Ogaki, Massao, and Reinhart. "What Can Explain Excess Smoothness and Sensitivity of State-Level Consumption?". Journal of Political Economy, 1998, 1078-1098.

[19] Piazzesi, Monika, and Schneider, Martin. "Inflation and the Price of Real Assets". University of Chicago, mimeo, 2006.

[20] Piazzesi, Monika, Schneider, Martin, and Sleale Tuzel. "Housing, consumption and asset pricing", Journal of Financial Economics, 83 (2007) 531-569.

[21] Siegel, Stephan "Consumption-based asset pricing: durable goods, adjustment costs, and aggregation", Working Paper, Columbia University (2004).

[22] Song,Inho. "Complementarity in Housing and Monetary Policy", Working Paper, (2009).

[23] Stokey,Nancy L. "Adjustment Costs and Consumption Behavior", Working Paper, (2007). 